SCIENCE AND TECHNOLOGY OF THIN FILMS 
This page is intentionally left blank 


\section{SCIENCE AND TECHNOLOGY OF THIN FILMS}

Edited by

F C Matacotta

International Centre for Theoretical Physics

Trieste, Italy and Consiglio Nazionale delle Ricerche - I.S.M. Bologna, Italy

\section{G Ottaviani}

Università di Modena

Modena, Italy 
Published by

World Scientific Publishing Co. Pte. Ltd.

P O Box 128, Farrer Road, Singapore 9128

USA office: Suite 1B, 1060 Main Street, River Edge, NJ 07661

UK office: 57 Shelton Street, Covent Garden, London WC2H 9HE

\section{British Library Cataloguing-in-Publication Data}

A catalogue record for this book is available from the British Library.

\section{Library of Congress Cataloging-in-Publication Data}

Science and technology of thin film / editors, F. C. Matacotta, G. Ottaviani

p. $\mathrm{cm}$.

Includes bibliographical references

ISBN 9810221932

1. Thin films. 2. Thin films -- Industrial applications.

I. Matacotta, F, C. II. Ottaviani, G.

QC176.83.S25 1995

530.4175 -- dc20

95-24958

CIP

Copyright $(1995$ by World Scientific Publishing Co. Pte. Ltd.

All rights reserved. This book, or parts thereof, may not be reproduced in any form or by any means, electronic or mechanical, including photocopying, recording or any information storage and retrieval system now known or to be invented, without written permission from the Publisher.

For photocopying of material in this volume, please pay a copying fee through the Copyright Clearance Center, Inc, 222 Rosewood Drive, Danvers, Massachusetts 01923, USA.

Printed in Singapore. 


\section{Preface}

The impact of thin films science and technology on modern life is immense. Thin films are currently used in so many aspects both of everyday life and sophisticated applications. The related technologies were introduced for the first time on industrial scale in 1962. Since then the economic relevance of the thin films market has steadily increased. For the sake of understanding the reasons of the strong research and development efforts that are presently focused in this area, it is interesting to consider the world-market figures of thin films devices. By far, their most important application is in the electronics industry. Practically, all the components of any device, from the most advanced VLSI circuit to the humblest carbon film resistor or gold plated pin of a connector, are manufactured using thin film processes. The semiconductor thin film industry had a market of 80 billions of US\$ (1993) expanding at an estimated rate of $14 \% / y e a r$.

Connected to the electronic devices market are two important, fast growing thin film applications: flat panel displays and data storage.

The flat panel display production is increasing at an estimated rate of 20\%/year. The total market in 1993 approached 4 billions of US\$. The introduction of thin film technologies and new light emitting materials is making these $100 \%$ solid state thin film devices more and more competitive with respect to the traditional cathodic tubes of TV and computer monitor screens.

Thin films are again playing the major role in data storage devices industry. In fact, in both magnetic memories (hard and floppy disks) and optical CD memories, the active part is a thin layer of a magnetic oxide or high reflectivity metal. The market for these two applications together was 2.2 billions of US\$ in 1992 and is expanding at a rate near to $20 \% / y e a r$.

The applications related to the electronic industry together represent the $94 \%$ of the total world market of thin films. The remaining share is divided in a large number of particular applications, some of them very important either for their everyday life use (for instance plastic and metal thin films for food processing and preservation, simple thin film optical devices in light bulbs, car projectors, windows) or for their advanced technological content. This last category of applications usually takes advantage from the unique functional performances shown by special material thin films.

The impressive figures related to the various applications of thin films and the associated market expansion are intimately linked to the continous advances in the research of new processes, materials and techniques. In tum, all the crucial developments that have been introduced during the last decades were made possible because of the better understanding of the basic mechanisms that govern the thin films growth.

The present volume consists of a collection of ten contributions that cover in detail different aspects of the broad field of thin film science and technology.

The order of presentation reflects the content of the papers starting from fundamental properties of the growth of the thin layers and ending with the presentation of special applications. 
The first two papers (P.B. Barna and M. Adamik; H. von Känel, N. Onda and L. Miglio) give an up-dated review of the basic aspects of the growth mechanisms going from polycrystal to single crystal layers. In particular, in the first paper fundamentals of structure formation are used to describe the evolution of the different morphology and texture of the growing layers. The second paper deals with heteroepitaxial growth mechanisms; the growth of iron silicides on silicon is considered in detail as a case study. The third contribution (A. Stella, P. Cheyssac and R. Kofman) describes the growth mechanisms and properties of nanoparticles. Despite the topic could seem not appropriate, we find extremely stimulating to compare the mechanisms governing the growth of threedimensional clusters and bi-dimensional thin films.

The second general aspect concerns film deposition techniques. The paper of G. Müller, M. Konijnenberg, G. Krafft and C. Schultheiss introduces a novel deposition technique that makes use of nanosecond high power pulsed electron beams to evaporate a large variety of materials, from polymers to complex oxides.

The possibility of deposition of new materials in the form of thin films is always related to the development of suitable deposition techniques. In this respect, the contribution of L.B. Hackenberger, L.J. Pilione and R. Messier reports on very recent results on the use of ion beam assisted deposition in the stabilisation of cubic boron nitride layers. The following paper of $\underline{H}$. Yanagi gives a detailed account for the enormous capability of MBE derived techniques for the deposition of organic ordered thin films and their possible technological impact.

The development of new materials and new deposition techniques goes together with advances in the physical characterisation of thin films. The two papers of B. Drévillon and P. Scardi are related to widely used experimental techniques like optical ellipsometry and $\mathrm{X}$-ray diffraction respectively. The reported detailed descriptions of advanced analytical methods that expand the capabilities of these quite common instruments open new ways to accurately characterise microscopic properties of thin films.

Thin films is an area where research easily finds technological applications of relevant economic impact. The paper of M.S. Colclough presents a review of recent results on superconducting thin film magnetometer devices realised with metallic and ceramic high $T_{C}$ superconductors. The last contribution by $\underline{D}$. Pribat, F. Plais, P. Legagneux and C. Reita introduces some of the most recent developments in the field of large area thin film technology for electronic applications.

Part of the contributed papers are related to lectures given during the ICTP-IUVSTA-AIV Workshop on "Science and Technology of Thin Films" that was held at ICTP, Trieste in March 1994.

Special thanks are due to Dr. M. Croset, responsible of the Liaison Committee of the IUVSTA for the kind help and assistance.

Finally, we are specially grateful to Mrs. Milena Poropat for her patient and careful collaboration in the preparation of the volume.

\section{Francesco Cino Matacotta} Giampiero Ottaviani 


\section{Contents}

Preface $\quad$ v

Growth mechanisms of polycrystalline thin films $\quad 1$

P.B. Barna and M. Adamik

Heteroepitaxy

H. von Känel, N. Onda and L. Miglio

Fundamental properties and developments of metallic and semiconducting nanoparticles
A. Stella, P. Cheyssac and R. Kofman

Thin film deposition by means of pulsed electron beam ablation

G. Müller, M. Konijnenberg, G. Krafft and C. Schultheiss

Bombardment stabilization of cubic boron nitride

L. B. Hackenberger, L.J. Pilione and R. Messier

Orientation-controlled organic thin films

H. Yanagi

Applications of spectroscopic ellipsometry to thin film characterisation

B. Drévillon

XRD line broadening and texture of thin films

P. Scardi

The SQUID magnetometer: an application of thin-film superconductors

M.S. Colclough

Thin films for large area electronics

D. Pribat, F. Plais, P. Legagneux and C. Reita 